\title{
On the objective of pedagogical cognition and on the scientificity criteria of its results
}

\author{
Mikhail A. Lukatskii, ${ }^{1, *}$ \\ ${ }^{1}$ ISED RAE, Laboratory of Theoretical Pedagogy and Philosophy of Education, 105062, Moscow, Russia
}

\begin{abstract}
The article is devoted to the consideration of issues related issues related to objectives of pedagogical cognition and to criteria of results' scientificity obtained during the implementation of pedagogical research initiatives. The theoretical approaches that define the paths of cognition of education phenomena by the pedagogical science are critically analyzed in the paper. The problem of the search for reserves of renewal and development by the modern pedagogical science is also comprehended in the article.
\end{abstract}

At any source, devoted to the examination of the phenomenon of science, the definition of science as a sphere of human activity can be detected. The activity oriented to obtaining and justification a true knowledge about the world. This definition explicitly specifies that the purpose of science is to obtain the truth. As soon as such a ponderous concept as truth appears, so at once it becomes clear that without its determination, without understanding what the word "truth" means, it turns essentially impossible to clear up what are the real goals of a particular science.

The theory of knowledge (gnoseology) provides an answer to the question: What is truth? The particular science accepts the answers given by gnoseology, building on that answer its concretely-scientific cognitive activity.

Today, a few different responses to this question are presented in gnoseology. One of these answers states that truth is such an idea that matches its object, namely, the idea understands this subject as it really is. The idea is declared false when it does not correspond to its subject, and does not understand it as it really is. For instance, the statement that the moon is a natural satellite of the Earth is true, because indeed, the moon is a natural satellite of the Earth. This understanding of the truth has come to science from the Antiquity by Plato and Aristotle. They considered that the idea about the subject can correspond to reality. Such an interpretation of the truth, usually referred to as "classical" concept of truth. Quite frequently it also referred to as "correspondence" theory of truth (from the English word "correspondence").

The classical concept of truth is rather widely spread. It complies with the requirements of common sense and consequently remains in demand for over two thousand years. Only at first sight this concept seems simple. According to this concept, the subject, in question is, objectively exists. This means that the knowledge of it must be objective. In other words the knowledge must be independent of the control of human desires, of their will and intellectual predilections. Truth must depend only on reality. But as truth is always a linguistic expression, it is very hard to speak about the correspondence of thought and reality. The thought is not a sensible image, which may be similar to the subject that produced this image. Sensual image (visual image) of visible cactus, which I can see can be like a cactus itself, but the thought of it is a statement, lexical construction, as it can be similar to a real cactus. In spite of the evident complexity of the above described faced by Correspondence theory of truth, it remains one of the most widely used in scientific knowledge, particularly in pedagogy. The pragmatic conception of truth also has been widely circulated in science. The meaning of this conception consists in the following: a statement is true if it operates, in other words, if its use leads to positive results, brings success.

The Pragmatic theory of truth was suggested in the late $19^{\text {th }}$ century by $\mathrm{Ch}$. Peirce, and then it has been modified by W. James and J. Dewey. The meaning of this conception is that it is not important, our understandings comply with the world itself or not, they look like the world itself, or not. Another thing is important, whether our understandings allow us to act effectively in the world, to solve problems facing us or not. If understandings allow it, then there is a reason to regard them as true. And this conception of truth has its supporters and opponents. Critics emphasize that human practice is constantly changing and what was useful in one historical period becomes less useful and sometimes unnecessary and harmful at another time. These critics ask not without guile, should this mean that the truth itself has changed. Today, the Pragmatic theory of truth competes with the aforementioned Correspondence 
theory of truth. Both theories find their place in a modern, ramified, scientific and pedagogical knowledge.

Another theory of truth, which is called the Conventional theory of truth, exists along with Correspondence and Pragmatic theories. It was proposed by H. Poincare, P. Duhem, E. Le Roy. The name of this theory indicates that a key role is given to the consent (conventions) between researchers on the issue of what the studied subject is. The theory of truth absolutizes the role of agreements between the scientists. Scientists do not accidentally act in this way. Referring to the history of science, scientists demonstrate what a great role in scientific knowledge the convention (definition of meanings of the basic scientific terms, the choice etalons and systems of measurement units, the adoption of a system of logical laws and regulations, etc.) has played. Scholars say that the science is inconceivable without conventions between them. All that is presented by the science is a conventional product, and to understand the truth also is only possible as convention. Truth is always historical, always socially determined, it depends on by what methods the knowledge about the subject is obtained, how the acquired knowledge are interpreted. And for this reason, those who adhere to the theory of truth insist that it is expedient to interpret it only as a convention. The Conventional theory of truth has found its place in the natural sciences and in the humanities. Presently it is inherent and in pedagogical science. There is quite a lot scientists-pedagogues who follow the logic of understanding suggested by the Conventional theory of truth.

The Coherence theory is yet another theory of truth. According to this theory, only that statement may be considered as true, which is in the systematic agreement with statements already accepted in science.

Only such a statement can be considered as true, which is a necessary element of systematic, holistic conception. On the proposal of the representatives of the Coherence theory of truth the holistic conception is characterized by the fact that not a single element of this conception can't be removed without destroying it.

In this theory the integrity is considered as the semantic factor of scientific knowledge and because of it the truth becomes derivative of integrity, in which every element is related with other and carries out its own function. In the context of a coherence conception of truth the separate judgment is impaired and loses meaning, if it is not merges with a holistic construction, describing and explaining the phenomenon being studied. The Coherence theory of truth is advantageously circulated in the so-called formal sciences as "Logical", "Mathematical". Under the conditions of more and more penetration of "Logical" and "Mathematical" atmosphere into the human sciences, the coherence theory of truth strengthens its position in these sciences. This occurs, in particular, in the pedagogy too, by entering into a "Logical" discipline format.

Therefore, at the present time, speaking about the goal of pedagogical science, consisting in obtaining and justification of true knowledge about the world of education, it can be argued that scientists-pedagogues sometimes understand the true knowledge as difficulty- combining and sometimes mutually exclusive statements. The estimation of scientific-pedagogical statements as truthful depends on which kind of theory of truth the scientist adheres to. For example, for a representative of the Correspondence theory of truth in pedagogy what is considered to be the truth, will not be treated as such for the representatives of the Pragmatic, Coherence, Conventional theories of truth, and vice versa.

The pedagogical science strives to acquisition of true knowledge about the world of education. Let us attempt to answer the question, what is knowledge itself, after understanding the truth in pedagogy.

Knowledge is a product of human consciousness as illusions, fabrications, fantasies, images, performances, etc. Since ancient times, people were worried about the question of how to separate knowledge from other forms of consciousness. The ancient people asked themselves about the difference between knowledge (episteme) and opinion (doxa). Until now this issue has not lost its relevance. Knowledge is the result of cognition. What is cognition? It is the acquisition of knowledge. The line of reasoning has brought us into a vicious circle. How can we open the circle? Modern scientists consider that knowledge is rationally justified assertion namely proven assertion confirmed by experience. All clearly understand that not all assertions that are used by science have evidential character and confirmed by experience. Many of the assertions considered as scientific, accepted on faith. Scientific knowledge today includes rationally founded assertion and assertion taken on trust. Aside from this, in the human sciences, there are the subjective opinions of scientists in a much greater degree than in the natural sciences. If the faith and subjective evaluation, neighboring evidential knowledge, find a place in science, there is a natural desire to understand the difference between science and non-science and parascience. Attempts like this are carried out long time ago. For this the scientific criteria are defined allowing demarcate scientific knowledge, from knowledge that is not scientific.

Science is an evolving institution. In the context of historical changes of the institute of science, the scientificity criteria also evolved over time. This is the criteria that define a regulatory and evaluative standard of scientific activity. And that is why, without exercising excursion into the history of pedagogy, without revealing legal bases specific to science in certain historical periods, it is not possible in principle carefully and reasonably to speculate about the essence and specifics of the criteria of scientificity of the modern pedagogical knowledge.

In the development of science, in particular, pedagogical science, such periods can be identified, which are characterized by drastic changes in the basics of the research activities. This in full measure relates also to a drastic change in the normative structures of pedagogical research, which are the scientific criteria. These periods entirely justified can be regarded as stages of formation of new types of scientific and pedagogical rationality. 
In studies devoted to the history the formation of a science usually three periods allocated within which the norms of reality research had been being appeared, formed and fixed in the consciousness of the scientific community, specific to its time. The sequence of change of types of scientific rationality, described in the works of the history of science, is as follows:

- Classical type of scientific rationality $\left(17^{\text {th }}\right.$ end of $19^{\text {th }}$ century.);

- Nonclassical type of scientific rationality (end of $19^{\text {th }}$ - middle of $20^{\text {th }}$ century.);

- Postnonclassical type of scientific rationality (middle of $20^{\text {th }}$ - to the present time).

The study of features of the development of pedagogical science demonstrates that this scheme is applicable only partially to the description of historical formation of this field of scientific knowledge.

In the period from the $17^{\text {th }}$ to the end of the $19^{\text {th }}$ century the pedagogy had been actively adopting the logic of scientific understanding. The logic of scientific understanding was inherent to leaders of science of this time, as the mathematics and physics, and then the classical type of scientific and pedagogical rationality was formed. The features of this type were:

- the understanding of the world of education as a sphere of progressive directed linear development;

- the understanding of education as a sphere of action of rigidly unequivocal determination;

- the understanding of education as a sphere in which the past determines the present as well as the present determines the future. In the classical type of scientific and pedagogical rationality the description of educational objects as themselves existing in a strictly specified coordinate system was considered possible. For this it considers it necessary to the elimination of everything that was related to the subject of scientific and pedagogical knowledge and was resented the process of study of educational realities. The pedagogical consideration of phenomena was based on unambiguous causal relationship. The pedagogy oriented towards the leading at that time disciplines mathematics and physics, and it became possible to formulate two scientificity criteria, standard of scientificity - logical noncontradiction and experimental acknowledgment (later it became known as the criterion of verification).

The study of pedagogical works allows us to conclude that the formal criterion of noncontradiction makes it possible to avoid the trivial meaninglessness. According to this criterion, formulated even by Aristotle, it is impossible to speak meaningfully about something, if that something in the same time is inherent and not inherent in the same in the same regard. The criterion allows to evaluate the theory from the standpoint of factual confirmability. If the "A" theory assumes the "B" empirical consequences, and that the "B" are observed, such a theory should be considered as experimental confirmed. If the theory does not correspond to the criterion of verification, then it can hardly be considered fully scientific.

The tendency to "lift up" the pedagogy up to mathematics and to bring it closer to a clear, strict, logically substantiated structure contributed to the emergence of the criterion of logical noncontradiction in the sphere of methodology of pedagogical knowledge. The criterion of logical noncontradiction in accordance with regulations dictated the necessity of constructing of pedagogical knowledge by logical argumentation and deduction from the discovered first foundations.

The successes in the field of physics in their turn forced the pedagogues-researchers of that period to apply to the topic of experimental knowledge test. The experimental approbation of knowledge was in the focus of research attention. This meant that the logical test of pedagogical truth has been declared fundamentally insufficient, and only evidence rooted in the experiment has been claimed justified. Essentially a new normative criterion was introduced into the pedagogy of science. The criterion of verification, which is based on normative dictated the necessity of factual data gathering by experimentation and their subsequent generalization. Pedagogical knowledge built on the verification criteria acquired hypothetical-deductive characteristics, that was understood as knowledge having probabilistic nature in varying degrees.

Since the end of the $19^{\text {th }}$ century a new, so-called nonclassical type of scientific rationality began to actively form in science. In the context of this process, new samples of the study of reality have emerged and claimed that different from the previous ones. The studies of reality carried out the only true way (by "photographing"). In contrast to this principle in the science of the truth the several descriptions and explanations of the investigated subject phenomenon, differing among themselves starts to operate.

In the framework of the classical type of scientific rationality the explanation and description of the investigated object took place on the "per se" principle, without indicating its investigation means. In the framework of nonclassical type of scientific rationality the obligatory account of peculiarities of means of obtaining information about an object becomes an essential requirement. These peculiarities of means are now understood as a means of exerting significant influence on investigation itself, and on the results obtained during the study. The methods of proving and substantiation of knowledge have changed, too. More flexible determination schemes appear in scientific knowledge, the role of the case begins to be recognized. The models of linear interpretation of the objects are replaced by multifactor models of explanation of the dynamic process of their formation. The non-classical rationality fully absorbs the comprehension of deep dependence of cultural phenomena from the social circumstances in full. In the early $20^{\text {th }}$ century the search of fundamental differences of the humanities from the natural sciences have intensively been carried. These searches have contributed to the emergence of nonclassical type of scientific rationality in the humanities. At that time the pedagogy focused on the humanitarian disciplines, which were becoming increasingly popular in science. This encouraged the pedagogy to the inclusion of humanitarian scientific criteria in its methodological basis. In the pedagogical 
science the scientist as a subject of cognition begins to be considered not only as a carrier of "mind", but as a human being who is influenced by emotions, feelings and emotional experiences in the framework of research activities carried out by him. The Russian pedagogy of the late $19^{\text {th }}$ - early $20^{\text {th }}$ century developed in line with the motion for a new, nonclassical type of scientific rationality with the relevant scientific criteria which included the criteria of beauty, heuristic, along with the criteria of logical consistency, verifiability.

The beauty criterion reflects the presence of harmony in the products of scientific and pedagogical creativity. The beauty criterion presents the characteristic of pedagogical knowledge on the side of the subjective satisfaction by the knowledge. Heuristic criterion allows to substantiate the choice of theory, concept, hypothesis from the standpoint of the potentiality of their expansion. This means that this criterion allows to substantiate choice of a theoretical construct by the possibility of its development or improvement. For example, just a few years ago it was seriously considered, that the activity approach to science has outlived itself. And more recently a number of articles have appeared in its support. In these articles, the possibility of its further development is substantiated (V.A. Lektorsky, Activity approach: Crisis or revival? [1]; V.M. Rozin, Values basis of the concept of activity in psychology and modern methodology [2]; M.A. Rozov, Reflection and activities [3]; V.S. Shvirev, Activity approach to understanding of "human phenomenon" (an attempt to contemporary comprehension) [4]).

However, the events that occurred in the country in the twenties of the $20^{\text {th }}$ century interrupted this process. In the pedagogy the unified standard of scientificity knowledge was established for a long time (over 70 years). This standard is substantially reproduced the standard that has been characteristic of the axiomatically outputted knowledge. It is known that the MarxistLeninist vision of the learning process was characterized by immutable definitions. On the basis of these definitions the appropriate educational conclusions have been made and the ways of transformation of the educational reality in the right direction have been developed. In this period in the Russian pedagogy a considerable number of educational researches appeared. That meet the requirements of the Soviet period and that, in essence, were built on the basis of the criterion of logical noncontradiction.

In the worldwide context the period beginning from the middle of the $20^{\text {th }}$ century and continuing to the present day is a stage of transition to the so-called post nonclassical type of rationality in science. For Postnonclassical type of rationality is characterized by the following:

- complete rejection of monologism;

- recognition of a plurality of competing approaches and the principled of falsifiability of theories;

- rejection of reductionism, elementarism, linearity.

Today it has become perfectly clear that the potential irrefutability of theory is not its dignity. If the theory is potentially irrefutable, it means that it contains within itself statements that are either trivial $(\mathrm{A}=\mathrm{A})$ or they contain the absolute truth, the achievement of which is impossible for the present state of science. The history of the development of science incontestably indicates that the growth of scientific knowledge is a dynamic process. In the context of this process, some theories disproved, other theories substantiated, and later also disproved in favor of the followings. In view of the fact that the process of knowledge is infinite, this process in principle can't be completed. That is why the falsification criterion plays an important role in the scientific knowledge that allows to separate the nonscientific assertion (namely, those that can't even be potentially disproved) from the scientific (for which always exists possibility of refutation). At present the intuition and different pragmatic characteristics, such as benefit, convenience, efficiency are integrated into the extended spectrum of the "Rationality" concept. The criterion of the "Use" concept (criterion of pragmatism) allows to evaluate the product of pedagogical knowledge in terms of convenience of its use.

In this type of rationality, which still continues to be formed, the human being acts as the main factor, who is regarded not only as an active participant of cognition, but as a systemically important factor of any research activities.

At present the postnonclassical comprehension of scientificity forces the researcher to interpret harder and tougher the knowledge not as an objective in itself but as a means of solving problems. For classical scientific rationality the vision of knowledge through the prism of its fundamental justification was typical, but for postnonclassical scientific rationality first of all the evaluation of knowledge on the part of its efficiency in solving human problems become typical. At the same time, respectively, the following is changing: exploratory behavior of scientists, methodological standards for assessment of the results of research activities, scientificity criteria of obtained knowledge. The existing scientific criteria do not ignore the role of socio-cultural factors in the implementation of research programs, and do not exclude the impact of moral norms and personal aptitudes of researcher on the results of his activities. This means that these criteria do not nullify the existence of an unrecoverable link of acquired knowledge about the object as with a feature of the means and operations of activities of their acquisition, as well as with the value-goal settings of researcher.

This type of scientific rationality, containing a core of ideas about the norms, principles, future-oriented methods of action, is still far from its final formation. The methodological searchings of modern pedagogical science are closely and directly related to attempts of assimilation of this new type of scientific rationality with its scientificity criteria that are radically different from the previous criteria.

The Russian pedagogy start being included into the global process of the search of new grounds of its scientific rationality only in the late $20^{\text {th }}$ century, after the departure of Marxism-Leninism from the arena as the mainstream vision of reality. In this respect, the domestic pedagogy is in a situation of scientific research of its self-identity. This complex process determines the 
circumstance that in the contemporary field of pedagogical investigations the studies are widely presented, which are based on different types of scientific rationality and also based on different scientific criteria. The panorama of contemporary scientific and pedagogical researches is presented by theoretical and applied workings out, which have grown up on an eclectic basis, which kaleidoscopically combines various types of scientific rationality, immanently including appropriate criteria of obtaining and building of knowledge.

\section{References}

1. V.A. Lektorskii, Activity approach: Crisis or revival? Science through humanist's eyes (Progress-Tradition, Moscow, 2005) [In Rus]

2. V.M. Rozin, Values basis of the concept of activity in psychology and modern methodology. Science through humanist's eyes (Progress-Tradition, Moscow, 2005) [In Rus]

3. M.A. Rozov, Reflection and activities. Science through humanist's eyes (Progress-Tradition, Moscow, 2005) [In Rus]

4. V.S. Shvirev, Activity approach to understanding of "human phenomenon" (an attempt to contemporary comprehension). Science through humanist's eyes (Progress-Tradition, Moscow, 2005) [In Rus] 